\title{
SEGREGAÇÃO DE FUNÇÕES NA ADMINISTRAÇÃO PÚBLICA FEDERAL COM ENFOQUE NA CONFORMIDADE CONTÁBIL
}

\section{ARTIGO ORIGINAL}

CAVALCANTE, Daiana de Fátima Moreira ${ }^{1}$

CAVALCANTE, Daiana de Fátima Moreira. Segregação de funções na administração pública federal com enfoque na conformidade contábil. Revista Científica Multidisciplinar Núcleo do Conhecimento. Ano 06, Ed. 04, Vol. 07, pp. 21 35. Abril de 2021. ISSN: 2448-0959, Link de acesso: https://www.nucleodoconhecimento.com.br/contabilidade/conformidade-contabil

\section{RESUMO}

A busca incessante pela eficácia e pela eficiência da máquina pública deve estar amparada por instrumentos de controle que permitam medir as ações públicas e favoreçam a melhoria do processo decisório daqueles que gerenciam os recursos públicos, ou seja, dos gestores públicos. O controle interno, com todos os seus objetivos e princípios, é um facilitador desse processo. Dito isto, este artigo investigou a importância da aplicação do princípio de controle interno denominado segregação de funções no desempenho das atividades do servidor público, com enfoque naquele responsável pela Conformidade Contábil de órgão da Administração Pública Federal. Adicionalmente, apresentamos alguns conceitos e objetivos do controle interno, bem como as definições do princípio de segregação de funções e da Conformidade Contábil. A metodologia adotada foi a pesquisa exploratória com revisão de bibliografias que tratam das temáticas abordadas. Com o estudo, demonstramos a importância da aplicação do princípio de controle interno denominado segregação de funções que permite uma melhor distribuição das atividades e das responsabilidades institucionais entre os servidores públicos, com

\footnotetext{
${ }^{1}$ Pós-Graduação em Controladoria, Auditoria e Perícia Contábil e Graduação em Ciências Contábeis.

RC: 82633

Disponível em:

https://www.nucleodoconhecimento.com.br/contabilidade/conformidade-contabil
} 
destaque para a execução da Conformidade Contábil. Concluimos, por fim, que a segregação de funções na execução da Conformidade Contábil gera maior confiabilidade das demonstrações contábeis e também mais segurança nos atos praticados pela gestão pública.

Palavras-Chave: Administração Pública, Controle Interno, Conformidade Contábil, Segregação de Funções.

\section{INTRODUÇÃO}

Primar pela adequada gestão dos recursos públicos é um anseio que transcede o âmbito institucional, mas alcança todos àqueles que têm interesse legítimo em conhecer e, principalmente, entender como são arrecadados e, especialmente, aplicados os tributos recolhidos aos cofres públicos.

$\mathrm{Na}$ conjuntura atual, assegurar a legitimidade dos processos administrativos, que também englobam a captação e a aplicação dos recursos públicos, garantir o cumprimento da finalidade da instituição pública que é o bem estar social e, também, mitigar ou, até mesmo, eliminar lacunas que possibilitem práticas ilícitas, fraudes e condutas desabonadoras por parte dos servidores públicos, tornaram-se uma inquietação constante na vida dos gestores públicos.

A Lei Complementar n 101 , de 4 de maio de 2000, também chamada de Lei de Responsabilidade Fiscal (LRF), trouxe consigo uma série de disposições e de normas de finanças públicas a serem observadas pelos gestores dos órgãos públicos, a fim de assegurar a transparência, a fiscalização e o controle social, exercido diretamente pelo cidadão, de forma individual ou em grupos organizados.

A irresponsabilidade na arrecadação e na aplicação dos recursos públicos, bem como a inobservância das normas estabelecidas, podem ocasionar, até mesmo, a demissão do servidor público, além de outras implicações legais, cíveis e criminais. 
Logo, todos os servidores públicos estão de alguma forma envolvidos na administração desses recursos e, portanto, devem zelar pela legalidade e pela eficiência na aplicação dos mesmos.

Assim, quanto mais pessoas envolvidas no processo, menores serão as chances de erros, fraudes ou prática de ações ilícitas. A distribuição das atribuições aos servidores públicos é um fator que pode aquietar e, ainda, resguardar os gestores públicos na condução das atividades institucionais.

Neste ponto, questionamos qual a importância da segregação de funções na Administração Pública Federal tendo em vista a execução da Conformidade Contábil? Diante do exposto, elaboramos o presente estudo que tem como objetivo principal demonstrar a necessidade da segregação de funções no desempenho das atividades do servidor público, com enfoque naquele responsável pela Conformidade Contábil de órgão da Administração Pública Federal.

Adicionalmente, objetivamos:

- conceituar controle interno;

- elencar objetivos do controle interno;

- definir o princípio de segregação de funções;

- apresentar a Conformidade Contábil, obrigatória no âmbito da Administração Pública Federal;

- e destacar a importância da segregação de funções no processo de Conformidade Contábil.

Salientamos que esse artigo partiu de uma revisão bibliográfica com consultas em livros especializados, leis, manuais, artigos, revistas técnicas, sítios de internet e outras fontes, que discutem as temáticas abordadas.

Inicialmente, discorremos sobre aspectos relevantes do controle interno e seus objetivos, e também apresentamos o princípio da segregação de funções. 
Posteriormente, destacamos aspectos concernentes à Conformidade Contábil, que deve ser obrigatoriamente executada pelos orgãos da Administração Pública Federal.

Em seguida, enfatizamos a relevância da segregação de funções nos processos administrativos, com foco na execução da Conformidade Contábil e, por fim, apresentamos as considerações finais.

\section{CONTROLE INTERNO}

O controle interno pode ser entendido como um conjunto de procedimentos estabelecidos pela instituição, no caso pela Administração Pública Federal, para garantir o cumprimento das normas e dos objetivos institucionais, além de auxiliar o profissional de contabilidade na formatação das informações a serem publicadas, na transparência dos atos de gestão pública e, especialmente, na prestação de contas à sociedade.

\subsection{CONCEITOS E OBJETIVOS}

Originária do idioma francês 'contrôle', para Chiavenato (2003, p. 635), controle pode ser entendido como "a função administrativa que consiste em medir o desempenho a fim de assegurar que os objetivos organizacionais e os planos estabelecidos sejam realizados".

Já para Attie (2011, p. 188),

O controle interno compreende o plano de organização e o conjunto coordenado dos métodos e medidas, adotados pela empresa, para proteger seu patrimônio, verificar a exatidão e a fidedignidade de seus dados contábeis, promover a eficiência operacional e encorajar a adesão à política traçada pela administração.

A nível federal, a implementação e a manutenção de um sistema de controle interno, que permita averiguar, entre outros aspectos, a legalidade, a legitimidade e a 
economicidade dos aspectos contábeis, financeiros, orçamentários e patrimoniais da União e das entidades da administração direta e indireta, é uma exigência constitucional. (Art. 70 da CF, 1988).

Dessa forma, a Constituição Federal de 1988, propôs um sistema integrado de controle interno que ultrapassou os clássicos controles financeiro e administrativo e abrangeu um conjunto de controles financeiros, gerenciais, administrativos e operacionais (GUERRA, 2005, apud CASTRO, 2007, p. 141).

Como consequência dessa exigência constitucional, em 6 de setembro de 2000, foi publicado o Decreto № 3.591, que instituiu o Sistema de Controle Interno do Poder Executivo Federal, dispondo ainda sobre organização e estrutura, finalidades, atividades e competências deste sistema.

Oliveira e D'Ávila (2002, p. 84), destacam que o objetivo do controle é:

\begin{abstract}
Verificar e assegurar os cumprimentos, às políticas e normas da companhia, incluindo o código de éticas nas relações comerciais e profissionais; obter informações adequadas, confiáveis, de qualidade e em tempo hábil, que sejam realmente úteis para as tomadas de decisões; prevenir erros e fraudes. Em caso de ocorrência dos mesmos, possibilitar a descoberta o mais rápido possível, determinar sua extensão e atribuições de corretas responsabilidades; registrar adequadamente as diversas operações, de modo a assegurar a eficiente utilização dos recursos da empresa; assegurar o processamento correto das transações da empresa, bem como a efetiva autorização de todos os gastos incorridos no período.
\end{abstract}

Assim, o funcionamento de um sistema é regulado por um sistema automático que monitora se a execução das tarefas e a avaliação das atividades, bem como dos resultados desejados, estão alinhados com o que foi elaborado no planejamento da organização. Logo, o controle exerce, também, tanto uma função restritiva quanto coercitiva visando garantir o alcance das metas e objetivos da instituição. (CHIAVENATO, 2003, p. 613). 
Além disso, o fator humano é essencial para o êxito do controle interno, tendo em vista que serão os colaboradores, cada qual com suas competências e atribuições específicas, que de fato executarão as atividades institucionais.

Attie (2007, p. 189) afirma que, "um sistema de controle interno que funcione corretamente não depende apenas do planejamento efetivo da empresa e da eficiência dos procedimentos e práticas instituídas, mas também da competência de todo pessoal envolvido".

Portanto, é fundamental que haja o engajamento de todos, porém, sem que a mesma pessoa execute, do início ao fim, fases críticas do processo, que podem comprometer a conformidade das operações.

Assim, a Instrução Normartiva no 1, de 6 de abril de 2001, da Secretaria Federal de Controle Interno da Controladoria-Geral da União relaciona os seguintes princípios de controle interno:

- a relação custo versus benefício;

- a qualificação adequada, treinamento e rodízio de funcionários;

- a delegação de poderes e definição de responsabilidades;

- a segregação de funções;

- os controles sobre as transações;

- e a aderência a diretrizes e normas legais.

Dentre esses princípios, destacamos o da segregação de funções, objeto do nosso estudo e que será detalhado a seguir.

\subsection{PRINCÍPIO DA SEGREGAÇÃO DE FUNÇÕES}

Segregar funções é o ato de separar, desmembrar fases de um processo para garantir a lisura e legitimidade das atividades de uma determinada instituição, que pode ser tanto pública quanto privada. 
Para o Conselho Federal de Contabilidade (CFC), NBC TA 315 (R1) de 19 de agosto de 2016, a segregação de funções é:

Atribuir a pessoas diferentes as responsabilidades de autorizar e registrar transações, bem como manter a custódia dos ativos. A segregação de funções destina-se a reduzir as oportunidades que permitam a qualquer pessoa estar em posição de perpetrar e de ocultar erros ou fraudes no curso normal das suas funções.

Portanto, é fundamental que as competências e as obrigações dos colaboradores ou dos setores internos da instituição sejam adequadamente discriminadas em manuais internos da organização. (ALMEIDA, 2003, p. 64).

Ainda, conforme Instrução Normartiva oㅜ 1, de 6 de abril de 2001, pelo princípio da segregação de funções as entidades devem desmembrar as funções de autorização/aprovação de operações, execução, controle e contabilização, ou seja, as fases cruciais do processo devem ser executadas, em regra, por agentes distintos, a fim de inibir irregularidades e fraudes.

Para Crepaldi (2004, p. 252), a segregação de funções visa "estabelecer que uma mesma pessoa não possa ter acesso aos ativos e aos registros contábeis, em virtude de essas funções serem incompatíveis dentro do sistema de controle interno da empresa".

No Sistema Integrado de Administração Financeira do Governo Federal (SIAFI), a Macrofunção SIAFI № 020315, que trata da Conformidade Contábil no âmbito da Administração Pública Federal, estabelece que:

8.1.1 - A segregação de funções consiste em princípio básico de controle interno administrativo que separa, por servidores distintos, as funções de autorização, aprovação, execução, controle e contabilidade.

Logo, ausente a segregação de funções, ocorre a fragilização do processo, e as consequências poderão ser danosas à instituição. 
No âmbito da Administração Pública Federal é ainda mais evidente a importância da aplicação deste princípio, uma vez que é composta por órgãos e entidades que administram recursos públicos e, portanto, devem reportar à sociedade suas ações e demonstrar a eficiência da gestão realizada.

Diante disso, necessitam possuir um sistema de controle interno robusto capaz de retratar com fidedignidade os atos de gestão que serão traduzidos em informações por meio da Contabilidade.

Uma das mais relevantes atividades desempenhadas pelo profissional da Contabilidade, na Administração Pública Federal, é a Conformidade Contábil, que apreciaremos no próximo tópico.

\section{CONFORMIDADE CONTÁBIL NA ADMINISTRAÇÃO PÚBLICA FEDERAL}

A Conformidade Contábil é regida pela Macrofunção SIAFI no 020315 que, em conjunto com outras Macrofunções, integram o Manual SIAFI, confeccionado pela Secretaria do Tesouro Nacional[2].

Neste manual estão registradas as normas e os procedimentos operacionais que devem ser observados pelo usuário no uso do SIAFI. Dentre os procedimentos operacionais, podemos destacar a Conformidade Contábil.

Na Macrofunção SIAFI no 020315,

2.1.1 - A Conformidade Contábil dos atos e fatos da gestão orçamentária, financeira e patrimonial consiste na certificação de que as demonstrações contábeis geradas pelo Sistema Integrado de Administração Financeira do Governo Federal (SIAFI) estão de acordo com a Lei no 4.320/1964, com o Manual de Contabilidade Aplicada ao Setor Público (MCASP) e com este Manual SIAFI.

RC: 82633

Disponível em:

https://www.nucleodoconhecimento.com.br/contabilidade/conformidade-contabil 
Depreende-se do exposto que ao conformista contábil cabe validar e atestar que o universo de operações ocorridas na instituição foram contabilizadas de forma coerente com os diversos normativos que regem a Contabilidade Pública.

É importante destacar ainda que Conformidade Contábil é diferente de Conformidade de Registro de Gestão.

A Macrofunção SIAFI no 020314, dispõe que a Conformidade de Registro de Gestão,

2.1 - Consiste na certificação dos registros dos atos e fatos de execução orçamentária, financeira e patrimonial incluídos no Sistema Integrado de Administração Financeira do Governo Federal - SIAFI e da existência de documentos hábeis que comprovem as operações.

Assim, a Conformidade de Registro de Gestão está ligada à certificação de que todos os registros dos atos e fatos da Unidade Gestora Executora obedeceram às normas vigentes, bem como à conferência de todos os documentos hábeis e idôneos que respaldaram os registros.

Por sua vez, a Conformidade Contábil está ligada ao ateste de que todos os registros mencionados anteriormente estão em conformidade com as normas e legislações que regem a Contabilidade Pública.

A seguir apresentamos um quadro com as principais diferenças entre Conformidade Contábil e Conformidade de Registro de Gestão.

Quadro 1: Conformidade Contábil versus Conformidade de Registro de Gestão

\section{Conformidade Contábil}

\section{Conformidade de Registro de Gestão}

Legislação: Macrofunção SIAFI no Legislação: Macrofunção SIAFI $\mathrm{n}^{0}$ 020315 020314

Objetivo: Certificar que as Objetivo: Certificar que todos os demonstrações contábeis geradas registros dos atos e fatos de execução 
pelo Sistema Integrado de orçamentária, financeira e patrimonial Administração Financeira do Governo foram incluídos no Sistema Integrado Federal (SIAFI) estejam de acordo com de Administração Financeira do a Lei no 4.320/1964, com o Manual de Governo Federal - SIAFI e que existem Contabilidade Aplicada ao Setor documentos hábeis que comprovem as Público (MCASP) e com o Manual operações SIAFI

Responsável: Profissional de Responsável: Servidor formalmente contabilidade devidamente registrado designado pelo titular da Unidade no Conselho Regional de Gestora Executora

Contabilidade - CRC, em dia com suas obrigações profissionais, credenciado no SIAFI para este fim

Periodicidade: Mensal e, no Periodicidade: Diária, devendo ser encerramento do Exercício Financeiro, registrada em até 3 dias úteis a contar com a emissão da Declaração do da data do registro da operação no Contador SIAFI

Transação no SIAFI: >ATUCONFCON Transação no SIAFI: >ATUCONFREG

Fonte: Autor, adaptado das Macrofunções SIAFI no 020315 e no 020314.

Tendo em vista que o conformista contábil é responsável pelo ateste das demonstrações contábeis, que por sua vez são estruturadas a partir dos registros dos atos e fatos de gestão no SIAFI, cuja responsabilidade é do conformista de registro de gestão, no próximo tópico iremos discorrer sobre a imprescindibilidade da segregação de funções para os fins de Conformidade Contábil na Administração Pública Federal. 


\section{A RELEVÂNCIA DA APLICAÇÃO DO PRINCÍPIO DE SEGREGAÇÃO DE FUNÇÕES: A EXECUÇÃO DA CONFORMIDADE CONTÁBIL}

Executar a Conformidade Contábil é uma atribuição exclusiva do servidor conformista contábil, que está vedado de exercer funções que se relacionem com autorização, aprovação, execução e controle.

Conforme Macrofunção SIAFI no 020315:

8.1.2 - O conformista contábil, em observância ao princípio da segregação de função, não poderá, concomitantemente, exercer quaisquer funções conflitantes com sua atividade de realizar a conformidade contábil, tais como: autorizar, aprovar e executar registros de gestão ou ainda efetuar a conformidade de registro de gestão.

Por sua vez, a Macrofunção SIAFI no 020314, reforça que:

3.9.1 - Deve-se manter a separação das atribuições preservando em figuras distintas o responsável pela emissão dos documentos, o responsável pela Conformidade de Gestão e o contador responsável pela Conformidade Contábil, ou seja, o servidor que realize a função de emitir documentos não deve ser o mesmo responsável pelo registro da Conformidade de Registro de Gestão, nem tão pouco ser aquele responsável pelo registro da Conformidade Contábil.

Neste ponto, destacamos a segregação de funções, que objetiva impedir o mesmo indívido de controlar aquilo que executou, ou seja, de exercer atividades incompatíveis do ponto de vista administrativo.

No geral, alguns exemplos que podemos citar são:

- a pessoa responsável pela compra seja a mesma que ateste o recebimento de um material ou produto;

- a pessoa que atesta o recebimento do material seja a mesma que execute a liquidação e o pagamento;

RC: 82633

Disponível em:

https://www.nucleodoconhecimento.com.br/contabilidade/conformidade-contabil 
- a pessoa que execute o pagamento seja a mesma que faça a Contabilidade, entre outros.

No âmbito da Administração Pública Federal, o Acórdão 2072/2007-TCU-Plenário TCU, determina que os gestores públicos devem "1.3 observar o disposto na IN/SFC no 01/2001, designando servidores distintos para as funções de "Encarregado do Setor Financeiro" e de "Responsável pela Contabilidade", que devem ser segregadas;".

Analisando alguns Acórdãos emitidos pelo Tribunal de Contas da União - TCU, que é o órgão responsável pelo controle externo da Administração Pública Federal, percebemos que é recomendação constante deste órgão a observância do princípio da segregação de funções, como demonstraremos a seguir.

O Acórdão 4701/2009-TCU-Primeira Câmara, define que a Administração Pública deve abster-se de nomear servidores, que tenham vínculo com o setor financeiro da unidade, para acompanhamento e fiscalização de contratos. Da mesma forma, o Acórdão 3281/2008-TCU-Primeira Câmara dispõe que o gestor público deve priorizar a designação de servidores distintos para as atribuições de atestar a realização de despesas e para pagamento da despesa executada.

Temos ainda o Acórdão 5615/2008-TCU-Segunda Câmara que designa ao administrador público,

1.7.1. Que observe em suas unidades gestoras o princípio de segregação de funções que consiste na separação de funções de autorização, aprovação, execução, controle e contabilização das operações, evitando o acúmulo de funções por parte de um mesmo servidor;

Diante de todo o exposto, é primordial que os gestores públicos, como uma boa prática, implementem todas as medidas necessárias para que sejam desmembradas e distribuídas, entre os servidores ou entre as equipes de servidores, as atividades de naturezas orçamentária, financeira, contábil e patrimonial. 
Tem-se, portanto, que o profissional de contabilidade, responsável pela Conformidade Contábil, limitar-se-á a desenvolver atividades que não comprometam o ateste das demonstrações contábeis, que deve ser isento de vícios e interferências, sejam elas internas ou externas.

Para finalizar o que discorremos ao longo deste trabalho, apresentamos, a seguir, um resumo das funções administrativas mais críticas que necessitam ser segregadas para não comprometerem todo o processo.

Fluxograma 1: Segregação de Funções Administrativas

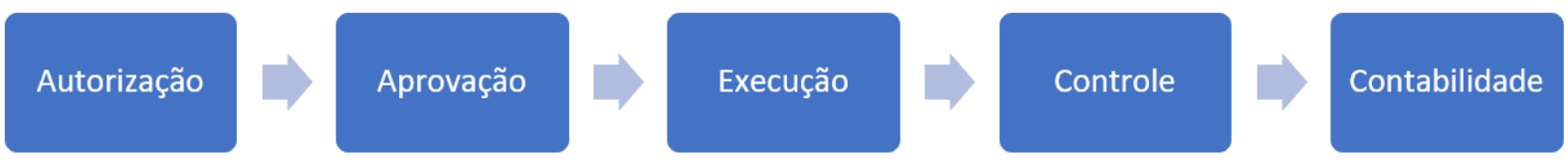

Fonte: Próprio Autor, baseado na Macrofunção SIAFI nº 020315.

\section{CONSIDERAÇÕES FINAIS}

Conhecer a realidade da instituição, incluindo seu contexto operacional e seus controles internos, é um dever imperioso dos gestores públicos. Esses têm o dever de prestar contas à sociedade e aos órgãos de controle sobre como os recursos estão se traduzindo em ações que concretizam as políticas públicas deliberadas, bem como aferir se tais recursos e poderes estão sendo usados em conformidade com os princípios de administração pública, as leis e os regulamentos aplicáveis.

Ao profissional de contabilidade também cabe essa importante tarefa, já que o mesmo é o responsável pela elaboração das demonstrações contábeis que refletirão a situação financeira, econômica e patrimonial de uma dada instituição em um dado período.

No âmbito da Administração Pública Federal, as demonstrações contábeis são estruturadas a partir do registro dos atos e fatos de gestão executados. Assim, mesmo a responsabilidade pela integralidade e confiabilidade das informações 
sendo do gestor público, o profissional de contabilidade é corresponsável pelas demonstrações divulgadas.

Nesse sentido, a segregação de funções é fundamental para garantir a lisura dos procedimentos administrativos, pois é uma atividade do controle interno que objetiva reduzir riscos e visa o alcance dos objetivos institucionais.

O profissional de contabilidade, responsável pela Conformidade Contábil, dada a importância dessa atribuição, deve atestar as demonstrações contábeis, certificando que todos os registros efetuados estão alinhados com as legislações e normas pertinentes à Contabilidade Pública.

É crucial que o conformista contábil não se envolva em atividades incompatíveis com sua função, já que o mesmo encontra-se na parte final do processo administrativo, não sendo apropriado que o mesmo execute atos e fatos de gestão que ao final do processo serão validados pelo próprio profissional.

Segregar funções, especialmente em relação àquele responsável pela Conformidade Contábil, faz-se necessário para eliminar ou, até mesmo, impedir condutas fraudulentas e ílicitas, como também erros que comprometam a confiabilidade, integridade e veracidade dos registros que, por sua vez, compõem as demonstrações contábeis, uma das diversas ferramentas utilizadas pela Administração Pública Federal para divulgação de seu desempenho e sua eficiência institucional.

\section{REFERÊNCIAS BIBLIOGRÁFICAS}

ALMEIDA, Marcelo Cavalcante. Auditoria: um curso moderno e completo. 5. Ed. São Paulo: Atlas, 2003.

ATTIE, William. Auditoria: conceitos e aplicações. 3. ed. São Paulo: Atlas, 2007. Auditoria: Conceitos e aplicações. 6. ed. São Paulo: Atlas, 2011. 
BRASIL. Constituição (1988). Constituição da República Federativa do Brasil: promulgada em 5 de outubro de 1988, Brasília, DF, 5 out. 1988. Disponível em <http://www.planalto.gov.br/ccivil_03/constituicao/constituicao.htm> Acesso em: 10 março 2021.

Decreto no 3.591. Dispõe sobre o Sistema de Controle Interno do Poder Executivo Federal e dá outras providências. Brasília, DF, 6 set. 2000. Disponível em: <http://www.planalto.gov.br/ccivil_03/decreto/d3591.htm> Acesso em: 10 mar. 2021.

Lei Complementar № 101. Estabelece normas de finanças públicas voltadas para a responsabilidade na gestão fiscal e dá outras providências. Brasília, DF, $4 \quad$ mai. 2000.2 Disponível em: <http://www.planalto.gov.br/ccivil_03/leis/lcp/lcp101.htm> Acesso em: 10 março 2021.

BRASIL. Ministério da Economia. Instrução Normativa no 01. Define diretrizes, princípios, conceitos e aprova normas técnicas para a atuação do Sistema de Controle Interno do Poder Executivo Federal. Brasília, DF, 06 abr. 2001. Disponível em: $<$ https://www.gov.br/suframa/pt-br/acesso-ainformacao/IN0106ABR2001MANUALDOSISTDECONTINTDOGOVFED.pdf/view> Acesso em: 11 mar. 2021.

- Ministério da Economia. Sistema Integrado de Administração Financeira do Governo Federal - SIAFI. Macrofunção - 020300. Conformidade de Registro de Gestão - 020314. Disponível em: $<$ https://conteudo.tesouro.gov.br/manuais/index.php?option=com_content\&view=artic le\&id=1550:020314-conformidade-de-registro-de-gestao\&catid=749\&ltemid=376> . Acesso em: 04 mar. 2021.

- Ministério da Economia. Sistema Integrado de Administração Financeira do Governo Federal - SIAFI. Macrofunção - 020300. Conformidade Contábil 020315.

Disponível

em:

RC: 82633

Disponível em:

https://www.nucleodoconhecimento.com.br/contabilidade/conformidade-contabil 
$<$ https://conteudo.tesouro.gov.br/manuais/index.php?option=com_content\&view=artic le\&id=1551:020315-conformidade-contabil\&catid=749\&ltemid=700 >. Acesso em: 04 mar. 2021.

BRASIL. Tribunal de Contas da União. Acórdão 2072/2007-TCU-Plenário. Relator: Ministro Valmir Campelo. Brasília, DF, 24 de julho de 2007. Disponível em: $<$ https://pesquisa.apps.tcu.gov.br/\#/documento/acordaocompleto/*/NUMACORDAO\%253A2072\%2520ANOACORDAO\%253A2007/DTRELE VANCIA\%2520desc\%252C\%2520NUMACORDAOINT\%2520desc/2/\%2520> Acesso em: 08 mar. 2021.

. Tribunal de Contas da União. Acórdão 3281/2008-TCU-Primeira Câmara. Relator: Ministro Marcos Bemquerer. Brasília, DF, 07 de outubro de 2008. Disponível em:

$<$ https://pesquisa.apps.tcu.gov.br/\#/documento/acordaocompleto/*/NUMACORDAO\%253A3281\%2520ANOACORDAO\%253A2008/DTRELE VANCIA\%2520desc\%252C\%2520NUMACORDAOINT\%2520desc/0/\%2520> Acesso em: 08 de mar. 2021.

. Tribunal de Contas da União. Acórdão 4701/2009-TCU-Primeira Câmara. Relator: Ministro Marcos Bemquerer. Brasília, DF, 01 de setembro de 2009. Disponível em: <https://pesquisa.apps.tcu.gov.br/\#/documento/acordaocompleto/*/NUMACORDAO\%253A4701\%2520ANOACORDAO\%253A2009/DTRELE VANCIA\%2520desc\%252C\%2520NUMACORDAOINT\%2520desc/1/\%2520> Acesso em: 08 mar. 2021.

- Tribunal de Contas da União. Acórdão 5615/2008-TCU-Segunda Câmara. Relator: Ministro Raimundo Carreiro. Brasília, DF, 03 de dezembro de 2008. Disponível em: < https://pesquisa.apps.tcu.gov.br/\#/documento/acordaocompleto/*/NUMACORDAO\%253A5615\%2520ANOACORDAO\%253A2008/DTRELE VANCIA\%2520desc\%252C\%2520NUMACORDAOINT\%2520desc/0/\%2520> Acesso em: 08 mar. 2021. 
CASTRO, Rodrigo Pironti de. Controle Interno da Administração Pública: Uma perspectiva do modelo de gestão administrativa. PUC - Paraná/Curitiba. 2007.

CHIAVENATO, Idalberto. Administração nos Novos Tempos. $2^{\underline{a}}$ edição. Rio de Janeiro, Campus, 2003.

CONSELHO FEDERAL DE CONTABILIDADE. Resolução CFC 2016/NBCTA315(R1), de 19 de agosto de 2016. Altera a NBC TA 315 que dispõe sobre a identificação e avaliação dos riscos de distorção relevante por meio do entendimento da entidade e do seu ambiente. Disponível em: $<$ https://www1.cfc.org.br/sisweb/SRE/docs/NBCTA315(R1).pdf>. Acesso em: 11 mar. 2004.

CREPALDI, Silvio Aparecido. Auditoria contábil: teoria e prática. 3. Ed. São Paulo: Atlas, 2004.

OLIVEIRA, Marcelo Aparecido Martins \& D’ÁVILA, Marcos Zähler. Conceitos e técnicas de controles internos de organizações. São Paulo: Nobel, 2002.

\section{APÊNDICE - REFERÊNCIA DE NOTA DE RODAPÉ}

2.

https://conteudo.tesouro.gov.br/manuais/index.php?option=com_content\&view=articl e\&id=1521:000300-apresentacao-do-manual\&catid $=741$ \&ltemid $=700$

Enviado: Março, 2021.

Aprovado: Abril, 2021. 